\title{
Hak Anak Indonesia Dan Perlindungan Hukum Di Kelurahan Bekasi Jaya
}

\author{
Adi Nurrohman ${ }^{1}$ \\ Universitas Bhayangkara Jakarta Raya, adinurrohman@yahoo.co.id \\ Fransiska Novita Eleanora ${ }^{2}$ \\ Universitas Bhayangkara Jakarta Raya, vita_eleanor@yahoo.com
}

\begin{abstract}
Abstrak
Anak merupakan generasi penerus bangsa yang berhak atas perlindungan hukum yakni sejak berada dalam kandungan ibunya, sampai dilahirkan. Pemenuhan hakhak yang paling pokok diberikan adalah berhak atas kebutuhan pokoknya (sandang, pangan, dan papan), berhak atas pendidikan, pengajaran, kesehatan, tidak diskriminasi, dan menghargai pendapat anak khususnya anak-anak berada diwilayah Kelurahan Bekasi Jaya Kecamatan Bekasi Timur. Selain mendapatkan pendidikan di Kelurahan Bekasi Jaya Kecamatan Bekasi Timur, ini, perlu juga didapatkan hak-haknya seperti dalam penjealasan hak Asasi Manusia (HAM) yakni Undang-Undang No. 39 Tahun 1999. Secara jelas, pengaturan dalam bidang perdata dan pidana menyangkut hak-haknya. Perlindungan hukum atas identitas diri (akte kelahiran), adalah salah satu di bidang hukum perdata, dan sangat sulit untuk didapatkan untuk keluarga yang tergolong tidak mampu (keluarga miskin). Pemerintah menyediakan pembuatan akte kelahiran secara cuma-cuma dan tidak ada pemungutan biaya sepersen pun. bentuk perlindungan terhadap warganya, selain itu, seorang anak yang dilahirkan dari perkawinan campuran berhak untuk mendapatkan kewarganegaraan, jika masih dibawah umur, mengikuti warganegara ibunya, tetapi jika usianya diatas 18 tahun dan sudah dewasa, dapat menentukan mengikuti warganegara ayah atau ibunya. Perlindungan hukum di bidang hukum pidana, melindungi anak korban dan pelaku dari kejahatan atau pelanggaran yang terjadi sesuai Sistem peradilan Pidana Anak (SPPA), dalam pengaturan Undang-Undang Nomor 11 Tahun 2012. Dipisahkan dari orang dewasa, mendapatkan pengacara/advokat dalam penanganan masalah hukum, melakukan kegiatan rekreasional, tidak mengalami perlakuan yang melebihi batas kemanusiaan, serta merendahkan martabat atau derajatnya baik di lingkungan keluarga atau masyarakat, dimasukkan kepidana penjara, upaya terakhir adalah ditangkap, ditahan dan dituntut dimuka pengadilan, memberikan keadilan yang sesuai dengan aturan yang ada, identitasnya dirahasiakan untuk umum dan sidangnya harus bersifat tertutup agar kejiwaan/psikologinya tidak terganggu. Memperoleh pendampingan berdasarkan putusan pengadilan dan advokasi, serta dapat menyelesaikan kasusnya di luar pengadilan melalui diversi dengan menempuh restorative justice, yaitu prose penyelesaian perkara pidana anak dari formil ke informil untuk mendapatkan solusi atau persetujuan antara para pihak yang bersengketa.
\end{abstract}




\title{
JURNAL ABDIMAS UBJ
}

\section{Kata Kunci: Perlindungan, Hukum, Hak, Anak}

\begin{abstract}
The child is the next generation of the nation who is entitled to the protection of the law that is since in the womb being, until birth of his mother. The fulfillment of the most basic rights given is entitled to their basic needs (clothing, food, and boards), are entitled to education, teaching, health, non-discrimination, and respect the opinions of children, especially children located in Sub-District Bekasi Jaya, East Bekasi Sub district. In addition to getting education in Sub-District Bekasi Jaya, East Sub-district Bekasi, it is also get his rights as in necessary to the human rights issue, namely Law no. Law No. 39 of 1999. Clearly, civil and criminal arrangements concerning their rights. Legal protection of self-identity (birth certificate), is one in the field of civil law, and difficultand very to obtain for families who are classified as not able (poor families). The government provides free birth certificates and no collection. a child born of a mixed and to marriage shall have the right to acquire citizenship, if he is under age, to follow his mother's citizen, but if he is over 18 years of age and mature, may determine following the citizenship of his father or mother. Legal protection in the field of criminal law, protecting child victims and perpetrators of crimes or violations that occur under the Criminal Justice System of Children (SPPA) Law Number 11 Year 2012. Separated from adults, getting lawyers /advocates in handling legal issues, doing recreational activities, not subjected to treatment beyond the limits of humanity, as well as degrading or degrading both within the family or community environment, including imprisonment, the last resort being granted is arrested, detained and prosecuted before the court, giving justice in accordance with existing rules, and the trial must be closed so that the psychology / psychology is not disturbed. Obtaining counseling based on court decisions and advocacy, and solving cases outside the court through diversion through restorative justice, the process of settling child criminal cases from formal to informal to obtain solutions or agreements between the parties to the dispute.
\end{abstract}

Keywords: Protection, Legal, Rights, Child

\section{Pendahuluan}

Saling menghormati dan menghargai satu sama lainnya, termasuk juga kepada seorang anak merupakan wujud manusia yang terlahir dan diciptakan oleh Pencipta-Nya. Pemenuhan anak menyangkut haknya merupakan bentuk menjaga dan memberikan perlindungan terhadapnya, harkat dan martabat sudah melekat dalam dirinya sejak berada dalam kandungan ibunya, hak-haknya pun sudah melekat, dan anak tidak perlu memintanya. Hal ini tersirat didalam Perlindungan yang diberikaan untuk Anak yaitu Pasal 2 Undang-Undang No. 35 Tahun 2014, tentang harkat, dan martabatnya untuk tetap terjamin, berpartisipasi dan terlindungi dari segala ancaman dan hambatan, dan dapat hidup secaa optimal dan tidak mendapatkan tindakan diskriminasi, kekerasan yang tidak manusiawi.

Ketentuan ini, sesuai dengan aturan Nomor 36 tahun 1990 tentang Keputusan Presiden dimuat dan diadopsi dalam Hak Anak Dalam Konvensi (KHA) lalu 


\section{JURNAL ABDIMAS UBJ}

dijadikan prinsip-prinsip dalam Undang-Undang Perlindungan Anak No. 35 tahun 2014, Undang-Undang atau aturan ini menjelaskan bahwa Pemerintah wajib memberikan perlindungan dan pemenuhan anak-anak khususnya hak-haknya, dan siapapun yang melanggar aturan yang sudah ditetapkan tersebut serta mengelak tidak mau memberikan perlindungan dan pemenuhan yang layak kepada akan mendapatkan sanksi/hukuman yang setimpal dengan perbuatannya. Pemenuhan kebutuhan anak dan hak-haknya di kelurahan bekasi jaya kecamatan bekasi timur ini, selain pendidikan dan pengajaran yang sudah didapatkan oleh anak-anak tesebut, selain itu setiap sekolah yang dibangun dan berada di wilayah kelurahan bekasi jaya bisa dijadikan "sekolah ramah anak" bisa direalisasikan, artinya sekolah yang pendidikan dan programnya bisa mengedepankan hak-hak anak.

Anak-anak di kelurahan bekasi jaya ini mendapatkan hak-haknya, di antaranya hak untuk mendapatkan keamanan, kenyamanan, gedung sekolah, ruang belajar, ruang bermain. Termasuk fasilitas penunjang lainnya, anak harus mendapatkan perlakuan yang baik antar sesama komunitas sekolah. Udara yang cukup, ruang yang memadai, bangunan yang rapi serta fasilitasnya memadai sebagai layaknya sekolah. Anak harus merasa aman, nyaman, dan terpenuhi kebutuhannya, lebih ditujukan melalui perilaku siswanya, yakni sekolah yang bebas bullying. Selain pendidikan dan pengajaran, hak-hak lainnya seperti kesehatan juga harus didapatkan oleh seorang anak, hak-hak yang menyangkut bidang keperdataan dan Kepidanaan, mendapatkan hak identitas diri (akte kelahiran), sangat penting bagi seorang anak untuk mendapatkan hak atas anak mengenai identitas dan diri serta kewarganegaraan (jika anak tersebut dilahirkan beda warganegara berdasarkan perkawinan beda negara).

Pemahaman masyarakat tentang pentingnya identitas diri sianak, karena biayanya yang dibutuhkan mahal, tidak mengetahui prosedurnya, dan tidak tahu tujuannya, sering dijadikan pemahaman tidak mau mengurus identitas sianak tersebut. Sedangkan hak-hak dari segi kepidanaan lebih mengutamakan dan mengarahkan anak pelaku dan korban untuk tetap terpenuhinya hak-haknya sebagai anak berdasarkan Sistem Peradilan Pidana Anak (SPPA), dalam pengaturan Undang-Undang Nomor 11 tahun 2012, diisyaratkan bahwa anak harus tetap dipandang dengan manusiawi tidak memandang anak sebagai seseorang yang bersalah tetapi harus diberikan yang pembinaan kepada anak, agar kelak dirinya sadar dan tidak lagi perbuatannnya diulangi, dan sidang anak harus bersifat tertutup dan bertujuan agar psikologi/kejiwaan sianak jadi tidak terganggu. Dalam persidangan, tidak diperbolehkan hakim anak memakai jubah/toga di sidang tersebut, melainkan untuk wanita memakai blazer dan laki-laki memakai batik, dan dilaksanakan dalam keadaan tenang, tidak tegang didalam suatu ruangan tetutup, tidak ditonton oleh banyak orang.

Pemenuhan dilahirkan akan adanya hak-hak sejak kecil sampai dewasa harus tetap berorientasi pada segi perlindungan, anak tidak boleh dipekerjakan ataupun diperdagangkan. Baik memperdagangkan tubuhnya atau organ tubuhnya, menjual, menculik, menyekap atau dengan tindakan penipuan atau dilakukan pemerasan. Hal ini, tentunya dianggap suatu kejahatan besar, ataupun pelanggaran besar 


\section{JURNAL ABDIMAS UBJ}

bertentangan dengan Manusia dan hak serta asasinya (HAM) berat, perlindungan anak, dan kesejahteraan anak, dengan hal tersebut, dianggap si pelaku sudah melakukan kejahatan biasa yang sangat dahsyat (kejahatan kemanusiaan) (Rika Saraswati : 2015). Kurangnya kepedulian akan terlindungnya anak dan hak-haknya serta pemenuhannya menyebabkan banyaknya terjadi kasus pelanggaran yang berbahaya dan kasus kejahatan yang mengabaikan hak-hak anak, "stop kekerasan" terhadap anak, biarlah anak-anak harus tetap dilindungi, diberikan maksimal hukuman yang berupa perlindungan, sebagai benteng pertahanan. Pemenuhan akan hak-hak menjadi pertanggungjawaban dari Orangtuanya anak, Negara, Pemerintah dan masyarakat.

Tujuan dari masyarakat melakukan kegiatan secara pengabdian ini adalah :

a) Agar masyarakat kelurahan Bekasi Jaya Kecamatan Bekasi Timur mengetahui perlindungan hukum di Indonesia mencakup anak dan haknya

b) Penyuluhan hukum ini dapat mengetahui aturan perlindungan hukum serta sanksi yang mengaturnya

Manfaat dari masyarakat melakukan kegiatan yang dirumuskan oleh TIM Fakultas Hukum Universitas Bhayangkara Jakarta Raya, diharapkan agar :

a) Masyarakat kelurahan bekasi jaya kecamatan bekasi timur menyadari bahwa perlindungan hukum hak-hak anak tidak hanya menjadi tugas pemerintah dan tanggung jawab penegak hukum, melainkan masyarakat luas, terutama keluarga sebagai bagian terkecil.

b) Memahami sanksi yang mengatur perlindungan hukum akan bentuk penegakan hukum dalam rangka melindungi dan menjamin hak-hak anak Indonesia dan pemenuhannya.

Dalam mengkaji suatu permasalahan, teori-teori yang menjadi landasan tidak bisa dilepaskan, dalam memecahkan masalah yang hendak dikaji dan diteliti. Khususnya teori yang akan dikaji adalah Teori Perlindungan Hukum, berdasarkan urutannya ada 5 (lima) yaitu :

a) Perlindungan hukum diberikan kepada manusia yang merasa dirugikan oleh orang lain, dan juga masyarakat dapat menikmati hak-haknya secara luas.

b) Perlindungan hukum manusia akan hak asasinya adalah pengakuan akan harkat, martabat oleh setiap subyek hukum yang diberikan tanpa terkecuali.

c) Perlindungan hukum diberikan sebagai bentuk perlindungan menyeluruh yang diberikan penegak hukum yakni aparat agar masyarakat mendapatkan ketentraman, rasa aman, dan gangguan dan ancaman dari manapun.

d) Masyarakat diberikan perlindungan hukum yang mencakup aturanaturan kaidah dan sanksi-sanksi, dan hal tesebut merupakan mutlak dari hak masyarakat. 


\section{JURNAL ABDIMAS UBJ}

e) Hak dari subyek hukum berupa perlindungan hukum merupakan interaksi antara yang satu dengan yang lainnya dengan memiliki suatu kewajiban.

Selain itu, masyarakat harus memperhatikan sarana perlindungan hukum, yang harus diperhatikan oleh masyarakat kelurahan bekasi jaya kecamatan bekasi timur, yaitu :

a) Perlindungan Hukum Sarana Preventif

Masyarakat/subyek hukum jika merasa ada pertimbangan dalam keputusan dan seuatu pendapatnya dapat mengajukan keberatansecepatnya sebelum keeputusannya bersifat final/akhir. Disatu sisi pemerintah bersifat hati-hati dalam pengambilan keputusan, karena didasarkan kepada kebebasan bertindak.

b) Perlindungan Hukum Sarana Represif

Penanganannya dalam menyelesaikan sengketa/konflik yang terjadi dimasyarakat, pemenuhannya kepada anak dan haknya tetap akan diberikan, karena dikaitkan dengan prinsip negara hukum, dimana tujuan negara hukum untuk mendapatkan hak-hak asasi manusia., perlindungan, penegakan atau pengakuan (Philipus :1987)

Dengan kajian teori diatas, kegiatan pengabdian masyarakat dilaksanakan selama 1 (hari) yaitu pada hari Rabu, tanggal 31 Januari 2018, yang diikuti sekitar 65 peserta laki-laki dan perempuan diwilayah Kelurahan Bekasi Jaya - Kecamatan Bekasi Timur.

\section{Metode}

Sistem, bentuk atau tindakan apa yang dilakukan didalam memecahkan suatu masalah, tahapan-tahapan serta langkah-langkah yang dilakukan, agar mendapatkan hasil yang maksimal serta mempunyai manfaat terhadap masyarakat luas:

a) Analisa Situasi Masyarakat

Pemahman, pengetahuan masyarakat serta solusi perlindungan yang diberikan mengenai anak, yaitu dengan memberikan masukan dan arahan dalam memecahkan suatu masalah tentang haknya di Indonesia dalam masyarakat terjadi, yang solusi/jalan keluar ditinjau dari masalah yang dihadapai serta persepsi masalah dari masyarakat dalam menghadapi serta menyelesaikannya.

b) Identifikasi Masalah

Perspektif perlindungan dalam hukum Nasional yang meliputi aturan-aturan yang mengaturnya baik dalam aturan-aturan terhadap undang-undang perlindungan anak sendiri maupun dalam undang-undang Nasional, serta mengutamakan anak di bidang hukum pidana untuk dilindungi diutamakan sama dalam peradilan sistem dan diperlakukan sama di hadapan hukum sebagai seutuhnya manusia Indonesia. 


\section{JURNAL ABDIMAS UBJ}

c) Menentukan Tujuan Kerja

Kegiatan ini diharapkan sudah ada perubahan sebelum dan sesudah kegiatan tersebut terlaksana, pada hasilnya pre test dan post test, dilihat pre test tingkat pengetahuan dan pemahaman masyarakat relatif minim belum dapat mengetahui "perlindungan anak terhadap hak dan hukum", namun setelah diberikan post test pemahaman masyarakat lebih luas dan mengerti tentang bentuk, cara, sanksi, serta pencegahannya.

d) Rencana Pemecahan Masalah

Menekankan dan menguatkan Masyarakat betapa pentingnya landasan hukum serta perlindungan, pencegahan hukum dan Penegakan. Sosialisasi akan Undang-Undang Perlindungan Anak, Sistem Peradilan Pidana Anak (SPPA), Hak Asasi Manusia beserta Kitab Undang-Undang Hukum Pidana (KUHP), beserta sanksi yang mengaturnya serta menghukum pelaku dengan seberatberatnya jika terjadi pelanggaran/kejahatan menyangkut anak dan hak yang ada.

e) Pendekatan Sosial

Adanya masyarakat kelurahan bekasi jaya - kecamatan bekasi timur berupa tanya dan jawab yang dilakukan dengan sesi bertahap kepada narasumber, masyarakat sangat antusias dalam memberikan pertanyaan, dan disampaikan juga, jika hendak bertanya atau menemukan sesuatu fenomena yang terjadi dilingkungan masyarakat yang tinggal, bisa langsung datang ke FH Universitas Bhayangkara Jakarta Raya, Ke bagian Lembaga Konsultasi Bantuan Hukum $(\mathrm{LKBH})$, untuk mendapatkan bantuan hukum dalam penanganan kasus.

\section{Pelaksanaan Kegiatan}

Beberapa pelaksanaan dalam tahapan kegiatan :

a) Bagaimana kegiatan itu dilakukan

Kegiatan Pengabdian ini dilakukan dengan sosialisasi/penyuluhan, dari pihak kecamatan Bekasi Jaya - Kecamatan Bekasi Timur, kata sambutan disampaikan oleh Lurah, Bapak Ngadino, S.AP sedangkan dari pihak Universitas adalah Kabid Pengabdian kepada Masyarakat dan Kewirausahaan, Ibu Dr. Ir. Yatti Maryati Akib M.Si, dilanjutkan dengan 2 (dua) presentasi narasumber, yaitu Adi Nurrohman, SHI., M.Ag tentang perpektif hukum anak dan perlindungan nasional dan Fransiska Novita Eleanora, SH., M.Hum tentang bidang hukum pidana anak perlindungan dan pemenuhan hukum dan hak. Tanya dan jawab dilakasanakan setelah sesi presentasi.

b) Waktu Penetapan Pelaksanaan

Pengabdian berupa kegiatan kepada masyarakat ini dilaksanakan pada hari Rabu, tanggal 31 Januari 2018, Jam 09.30 - 12.30 wib

c) Penetapan Tempat Pelaksanaan Kegiatan

Kegiatan pengabdian kepada masyarakat dilaksanakan di Aula Kelurahan

Bekasi Jaya Kecamatan Bekasi Timur

d) Penetapan orang-orang yang terlibat dalam kegiatan pengabdian 


\section{JURNAL ABDIMAS UBJ}

Dari pihak kampus Bhayangkara Universitas Jakarta Raya mengikutsertakan beberapa mahasiswa, yang bertugas sebagai moderator, notulen, serta mengikuti sesi kegiatan pengabdian masyarakat di Fakultas Hukum. Warga masyarakat merasa senang dan antusias dengan sosialisasi yang dilakukan, melibatkan pihak Pembinaan Kesejahteraan Keluarga, pemuda-pemudi karang taruna, Rukun Tetangga ketuanya dan Ketua RW, dan jumlah masyarakat yang bertambah untuk mengikuti penyuluhan yang sedang berlangsung. Pihak dari Kelurahan Bekasi Jaya - Kecamatan Bekasi Timur melibatkan pihak Pembinaan Kesejahteraan Keluarga, pemuda-pemudi karang taruna, dan Rukun Tetangga dan Rukun Warga yaitu ketuanya. Warga masyarakat merasa senang dan antusias dengan sosialisasi yang dilakukan, ini dapat dilihat dengan jumlah masyarakat yang bertambah untuk melakukan penyuluhan yang sedang berlangsung.

e) Evaluasi Kegiatan dan Hasil

Kegiatan pengabdian yang sudah dilakukan, mencakup warga kelurahan bekasi jaya - kecamatan bekasi timur, yaitu ibu-ibu PKK, Karang Taruna, dan ada beberapa perwakilan dari pihak Rukun Tetangga (RT) dan Rukun Warga (RW), hasil yang dicapai cukup dimuaskan, bisa dikatakan $89 \%$ dari warga yang mengikuti pengabdian sudah paham dan mengerti tentang materi yang dipaparkan, dan bisa dibuktikan dari post test yang telah dibagikan, menunjukkan sudah ada perubahan sebelum ada kegiatan kepada pengabdian kepada masyarakat. Namun, bisa diperluas untuk kedepannya dengan melibatkan, ibu-ibu penggajian, pengurus-pengurus kelurahan. Dengan pengabdian ini harapan kedepan agar dapat mewujudkan pola perlindungan hukum, hukum dan pendidikan serta hukum dan pelayanannya yang berkesinambungan menuju masyarakat yang adil dan sejahtera, peran perguruan tinggi sebagai fasilitator dan mediator dalam memberikan arahan agar dapat terwujud.

\section{Hasil Dan Pembahasan}

Lebih menitikberatkan kemampuan dari warga masyarakat kelurahan bekasi jaya - kecamatan bekasi timur mengikuti pengabdian dalam menganalisis bentuk perlindungan hukum, serta dikaitkan/direalisasikan dengan kasus kejahatan terhadap anak.

Kelurahan Bekasi Jaya-Kecamatan Bekai Timur masih berada ditengah kota, dan bukan dipelosok pedesaan (daerah tepencil), maka sebagian besar pekerjaan dari masyarakatnya adalah Pegawai Negari Sipil (PNS), Swasta, Pedagang, dan Guru. Namun, pemahaman mereka kurang masalah anak terhadap perlindungan, khususnya dalam mencari solusi terhadap masalah yang dihadapi serta penerapan aturan hukum. Tabel 1 berikut merupakan luaran dari kegiatan pengabdian kepada masyarakat. 
Tabel 1. Luaran yang Diharapkan

\begin{tabular}{|c|l|l|l|}
\hline No & \multicolumn{1}{|c|}{ Unsur } & \multicolumn{1}{|c|}{ Pra Pengabdian } & \multicolumn{1}{|c|}{ Pasca Pengabdian } \\
\hline 1 & $\begin{array}{l}\text { Perpektif hukum anak } \\
\text { dan perlindungan } \\
\text { nasional }\end{array}$ & $\begin{array}{l}\text { Belum memahami } \\
\text { Perpektif hukum } \\
\text { anak dan } \\
\text { perlindungan } \\
\text { nasional }\end{array}$ & $\begin{array}{l}\text { Sudah memahami dan } \\
\text { menerapkan perpektif } \\
\text { hukum anak dan } \\
\text { perlindungan nasional }\end{array}$ \\
\hline 2 & $\begin{array}{l}\text { Bidang hukum pidana } \\
\text { anak perlindungan dan } \\
\text { pemenuhan hukum dan } \\
\text { hak. }\end{array}$ & $\begin{array}{l}\text { Belum memahami } \\
\text { dan mengerti Bidang } \\
\text { hukum pidana anak } \\
\text { perlindungan dan } \\
\text { pemenuhan hukum } \\
\text { dan hak. }\end{array}$ & $\begin{array}{l}\text { Sudah memahami dan } \\
\text { mengerti perpektif } \\
\text { pukum anak dan } \\
\text { perlindungan nasional }\end{array}$ \\
\hline
\end{tabular}

\section{Hasil Pengamatan Sebelum Pra Pengabdian}

Dari tabel 1 di atas, bahwa sebelum pra pengabdian belum memahami bagaimana perspektif anak perlindungan hukum nasional bisa dikatakan hanya dilihat dari majalah dan surat kabar, isu-isu aktual hak pemenuhan saja yang didengar dari siaran televisi, belum ada penyuluhan/sosialisasi secara spesifik tentang pengertiannya dan batasannya tersebut, dan bisa dikatakan radio, surat kabar ataupun majalah.

Hasil pengamatan I, juga didapatkan bahwa ada masyarakat kelurahan bekasi jaya kecamatan bekasi baru memahami bahwa hukum dari aspek perlindungannya bagi anak seperti tidak diskriminasi, memberikan penghargaan terhadap pandangan anak, hak kelangsungan hidup, kepentingan yang utama anak dalam kehidupannya, perkembangan serta kelangsungan kedepannya bagi layaknya kehidupan anak. Dari hasil pretest ditemukan hasil, 68\% responden menjawab, bahwa terjadinya anak yang mengalami pelanggaran berkaitan hak, dikarenakan :

a) Faktor tingginya kemerosotan kehidupan

b) Lemahnya pemahaman keluarga orang tua, masyarakat dan pemerintah terhadap hak anak

c) Kurangnya optimalisasi peran dari masyarakat pendukung, serta keluarga masyarakat

d) Upaya pencegahan seminimal mungkin kekerasan yang ditujukan pada anak (Waluyadi : 2009)

Perspektif perlindungan nasional juga mengatur siapa anak yang seharusnya bertanggung jawab terhadap perlindungan anak, adalah keluarga, orang tua, Negara, pertanggungjawaban masyarakat beserta jajaran pemerintah ini sudah diatur didalam ketentuan undang-undang sebagai anak dan manusia beserta implementasi pengaturan perlindungan asasi hak. 


\section{JURNAL ABDIMAS UBJ}

Hasil pengamatan II, masyarakat Bekasi Jaya Kecamatan Bekasi Timur belum sepenuhnya mengetahui dalam cakupan pemberian hukum pidana anak/hak-hak anak selama berada dalam masa tahanan, berhak bersama dengan keluarganya berhubungan, berhak untuk beribadah, persidangan yang tertutup dan tidak boleh dibuka untuk umum dan kerahasian identitas anak. Di samping itu, ada pendekatan diversi mekanismenya diselesaikan sesuai jalur pengadilan (pendekatan formal dan informal) agar anak dapat lebih terlindungi.

\section{Hasil Pengamatan Setelah Pasca Pengabdian}

Hasil pengamatan I, setelah dilakukan penyuluhan/sosialisasi, dan dibuka dengan jawab dan tanya berupa sesi, maka dapat dilihat masyarakatan kelurahan bekasi jaya kecamatan bekasi selatan sudah memahami dan dapat menerapkan Hak Anak Indonesia dan Perlindungan Hukum Nasional.

Narasumber lebih fokus menjelaskan berdasarkan prinsip-prinsip perlindungan anak, yakni Sistem Peradilan Pidana Anak Undang-Undang No. 11 Tahun 2012, yaitu :

a) Perlindungan

b) Keadilan

c) Nondiskriminasi

d) Anak mendapatkan kepentingan yang terbaik

e) Penghargaan terhadap pandangan anak

f) Anak mendapatkan tumbuh dan kembang dihidup serta kelangsungan kedepan

g) Memperoleh Pembimbingan yang sesuia dan Pembinaan mentalnya

h) Sama rata, seuai haknya

i) Upaya terakhir merupakan pemidanaan dan pengurangan kebebasan

j) Penghindaran pembalasan (Wagiati : 2010)

Pemaparan prinsip-prinsip perlindungan anak kepada masyarakat kelurahan Bekasi Jaya Kecamatan Bekasi Timur, menunjukkan bahwa masyarakat sudah memahami anak perepektif hukum nasional serta aturan-aturan perlindungan, dan dapat mengimplementasikan dalam kehidupan masyarakat serta lingkungan tempat tinggal.

Hasil pengamatan II, sudah memahami dan mengerti perlindungan anak dalam bidang hukum pidana beserta aturannya. Penghukuman anak merupakan upaya paling terakhir, psikologi dan kejiwaan anak harus benar-benar diperhatikan, dengan adanya sistem diversi, diartikan ada perlindungan maemadai bagi hak-hak anak, tidak mengisyaratkan anak harus dimasukkan kedalam Lembaga Pembinaan Khusus Anak (LPKA), tetapi antara korban dan pelaku saling bertemu untuk mengemukakan masalah serta ganti rugi yang didapatkan korban.

Penyelesaian perkara anak dilakukan melalui Diversi pengalihan dengan restorative justice pendekatan, pihak anatara korban pe;aku bertemu membahas kesepakatan. Dan batas waktu hanya 30 hari dilakukan. (Pasal 6, Sistem Peradilan Pidana Anak (SPPA), dalam UU No.or 11 Tahun 2012.). Dengan pemaparan oleh 2 


\section{JURNAL ABDIMAS UBJ}

(dua) Narasumber di Kelurahan Bekasi Jaya, Kecamatan Bekasi Timur, maka pemahaman, pengetahuan masyarakat terhadap anak, khususnya perlindungan anak, prinsip-prinsip perlindungan anak serta terjadinya konflik dimasyarakat, sudah dapat dipahami, diselesaikan dengan membuka wawasan masyarakat tersebut.

\section{Simpulan dan Rekomendasi}

Dari pembahasan di atas maka dapat ditarik kesimpulan dari seluruh kajian :

1. Hak anak Indonesia dan perlindungan hukum nasional meliputi prinsip nondiskriminasi, kepentingan terbaik, penghargaan pendapat anak baik dalam hukum pidana anak beserta kelangsungan hidupnya diperlukan perlindungan menyeluruh.

2. Hukum pidana anak dan perlindunga, Lembaga Pembinaan Khusus Anak (LPKA), dapat juga diselesaikan melalui diversi menuju keadilan restorative justice anak dan hak yang ada.

Adapun rekomendasi dari kegiatan pengabdian kepada masyarakat adalah:

1. Peran masyarakat terhadap perlindungan anak adalh fokus utama, dikarenakan pembimbingan anak dimulai dari yang paling rendah, terkecil adalah keluarga lalu masyarakat tempat tinggal, dengan pemahaman perlu adanya sosialisasi berkelanjutan terhadap perlindungan anak dilingkungan kelurahan bekasi jaya kevamatan bekasi timur.

2. Perlu adanya koordinasi/kerjasama antar pihak kelurahan, jika ada kasuskasus anak, dan dapat diakomodir oleh pihak Universitas, dengan ketersedianya Lembaga Konsultasi Bantuan Hukum (LKBH).

\section{Daftar Pustaka}

Philipus M. Hadjon, Perlindungan Hukum Bagi Rakyat Indonesia, Cetakan Pertama, Surabaya, Bina Ilmu, 1987

Rika Saraswati, Hukum Perlindungan Anak Di Indonesia, Cetakan kedua, Citra Aditya Bakti, Bandung, 2015

Wagiati Sotodjo, Hukum Pidana Anak, Cetakan Ketiga, Refika Aditama, Bandung, 2010

Waluyadi, Hukum Perlindungan Anak, Cetakan Pertama, Mandar Maju, Bandung, 2009

Undang-Undang Nomor 35 Tahun 2014 tentang Perlindungan Anak 
JURNAL ABDIMAS UBJ

Undang-Undang Nomor 11 Tahun 2012 tentang Sistem Peradilan Pidana Anak (SPPA)

Undang-Undang Nomor 39 Tahun 1999 tentang Hak Asasi Manusia (HAM)

Keputusan Presiden Nomor 36 Tahun 1990 tentang Pengesahan Konvensi Tentang Hak-Hak Anak 